\title{
Role of white light intensity and photoperiod during retail in broccoli shelf-life
}

\author{
Federico M. Pintos ${ }^{\text {a, b }}$, Joaquín H. Hasperué ${ }^{\mathrm{b}}$, Ariel R. Vicente ${ }^{\mathrm{b}}$, Luis M. Rodoni ${ }^{\mathrm{b}}{ }^{*}$ \\ a Centro de Investigación y Desarrollo en Criotecnología de Alimentos (CIDCA, CCT La Plata, CONICET, Facultad de Cs. Exactas UNLP), Calle 47 esq. 116, La Plata, CP. 1900, Buenos Aires, \\ Argentina \\ b Laboratorio de Investigación en Productos Agroindustriales (LIPA), Facultad de Cs. Agrarias y Forestales, Universidad Nacional de La Plata, Calle 60 y 119, La Plata, CP. 1900, Buenos Aires, \\ Argentina
}

\section{A R T I C L E IN F O}

\section{Keywords:}

Bassica oleracea var. Italica

Light

Senescence

Chlorophylls

Antioxidants

\begin{abstract}
A B S T R A C T
White light illumination during retail has been suggested as a simple, non-chemical way to extend the shelf-life of green vegetables. Unfortunately, the influence that key factors like radiation intensity and photoperiod have on the efficacy of such treatments efficacy is barely understood. Herein, we evaluated the influence that the intensity and photoperiod of white light illumination during retail, had on the shelf-life of cold stored broccoli. Broccoli florets were stored at $5{ }^{\circ} \mathrm{C}$ and illuminated with white light emitting diodes (LEDs) under three different light intensities (Low, 3.6; Mid, 9.5; and High, 19.0 W m ${ }^{-2}$ ). At each light intensity condition samples were subjected to four different light:darkness cycles ( $3 \mathrm{~h}: 21 \mathrm{~h} ; 6 \mathrm{~h}: 18 \mathrm{~h} ; 12 \mathrm{~h}: 12 \mathrm{~h}$ or $24 \mathrm{~h}: 0 \mathrm{~h})$. One set of samples packed and stored at $5^{\circ} \mathrm{C}$, but kept in darkness, was used as a control. After 0,11 or $19 \mathrm{~d}$ of storage we evaluated weight loss, color, chlorophylls, total sugars, sucrose, glucose and fructose contents. We also assessed the changes in ascorbic acid, carotenoids and phenolic antioxidants. Mid- and High-intensitytreatments proved highly beneficial to delay senescence. Storage under Mid-and High-intensity white LEDs for 3-12 h per day was markedly more effective to prevent yellowing than continuous illumination. Exposure to Mid-intensity light, $3 \mathrm{~h}$ a day also reduced dehydration, chlorophyll, sucrose, glucose and fructose losses. In addition, broccoli maintained higher levels of ascorbic acid, carotenoids and phenolics at the end of the storage period. These results show that white LED illumination during retail may be used to extend the shelf-life of refrigerated broccoli and set the stage for proper intensity and photoperiod usage.
\end{abstract}

\section{Introduction}

Broccoli is harvested, for maximum quality, when the heads are actively developing (Martínez-Hernández et al., 2013). Thus, without a tightly adjusted postharvest handling program in place, it will loss quality extremely rapidly (Rybarczyk-Plonska et al., 2014). Indeed, chloroplast dismantling and florets yellowing would occur at room temperature within one to two days (Costa et al., 2006; Jin et al., 2015). Senescence also comprises a number of other undesirable changes, including weight loss, sugar losses, antioxidant degradation and off-odors development (Lemoine et al., 2009; Fukasawa et al., 2010).

Proper temperature management is known to extend the shelf-life of broccoli inflorescences by 10-15 d, but short after that, rapid deterioration will occur. Consequently, there has been interest in the search of supplementary postharvest tools. A number of strategies have been tested so far to improve the storage capacity of refrigerated broccoli, though with variable success. 1-methylcyclopropene (1-MCP) effectively delayed broccoli senescence (Fan and Mattheis, 2000). However, due to economic constraints it is seldom used commercially for this purpose. Low $\mathrm{O}_{2}(0.25-0.50 \mathrm{kPa})$ modified atmospheres could extend broccoli shelf-life, but may induce undesirable sulfur-volatiles even if relatively small temperature fluctuations occur (Izumi et al., 1996; Li et al., 2016). Emerging technologies such as UV irradiation (Darré et al., 2017) or edible coatings (Moreira et al., 2011), have been reported to delay senescence in broccoli, but have not been applied so far beyond a lab scale.

Recent progressin the production of light sources has expanded the potential of illumination treatments for food and agricultural applications (Ilić and Fallik, 2017). Light emitting diodes (LEDs) generate lower heat, are more energy efficient and have longer lifespan than traditional lighting technology (Bantis et al., 2018). This, together with the fact that several plant light-sensing elements remain active after harvest (Liu et al., 2015), has renewed the interest in using illumination to extend produce storability.

In broccoli, continuous illumination delayed pheophytinase expression and chlorophyll degradation (Büchert et al., 2011). Exposure to white light for $12 \mathrm{~h}$ per day also proved effective to extend broccoli shelf-life (Jin et al., 2015). These studies conducted in non-refrigerated conditions provided a fundamental basis regarding the biological re-

\footnotetext{
* Corresponding author.

Email address: luisrodoni@agro.unlp.edu.ar (L.M. Rodoni)
} 


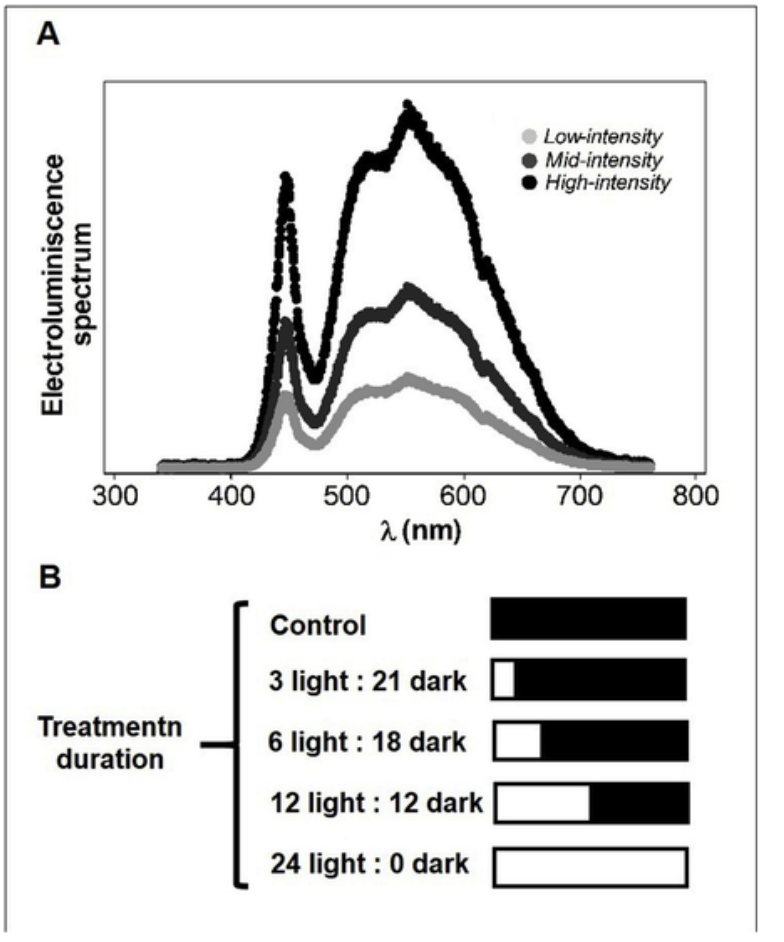

Fig. 1. A. Electroluminescence spectrum of the white LED sources used recorded at the surface of the broccoli trays for Low-Mid- and High-intensity treatments. B. Scheme of the different photoperiods used in this study to illuminate the trays of refrigerated broccoli during retail. sponses of fresh vegetables to postharvest illumination. However, complementary works at temperatures normally used for broccoli distribution $\left(0-5^{\circ} \mathrm{C}\right)$ are needed to establish their technological potential. Strikingly, quite few works have evaluated the benefits of postharvest visible light supplementation in refrigerated commodities. Moreover, the results reported in the literature have been highly variable, ranging from improved storability (Charles et al., 2018) to absence of major responses (Olarte et al., 2009) or even accelerated deterioration (Sanz et al., 2009; Xiao et al., 2014). This disparity may be, at least in part, due to the use of different lighting conditions (radiation source, dose, photoperiod and/or intensity). Strikingly, the influence that some of these key factors have, on the efficacy of postharvest illumination treatments, of cold stored commodities, is barely understood. The aim of this work was to understand the influence of radiation intensity and irradiation time on the efficacy of postharvest illumination treatments in green vegetables. We evaluated the role of white LED light intensity and photoperiod during retail on broccoli senescence.

\section{Materials and methods}

\subsection{Plant material treatments and storage}

Broccoli heads (Brassica oleracea var. Italica cv. Legacy) produced

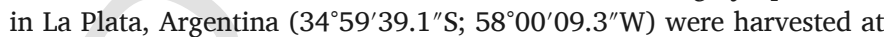
commercial maturity, and immediately transported to the laboratory. Samples having defects or physical damage were discarded and the selected inflorescences were washed in chlorinated water $\left(150 \mathrm{mg} \mathrm{L}^{-1}\right.$ as sodium hypochlorite, $\mathrm{pH}$ 6.5) for $2 \mathrm{~min}$. The inflorescences were cut with a sharp knife and florets weighting approximately $20 \mathrm{~g}$ were prepared and rinsed in chlorinated water, drained and packed in plastic trays $(17 \times 12 \times 5 \mathrm{~cm})$ and covered with perforated PVC film.

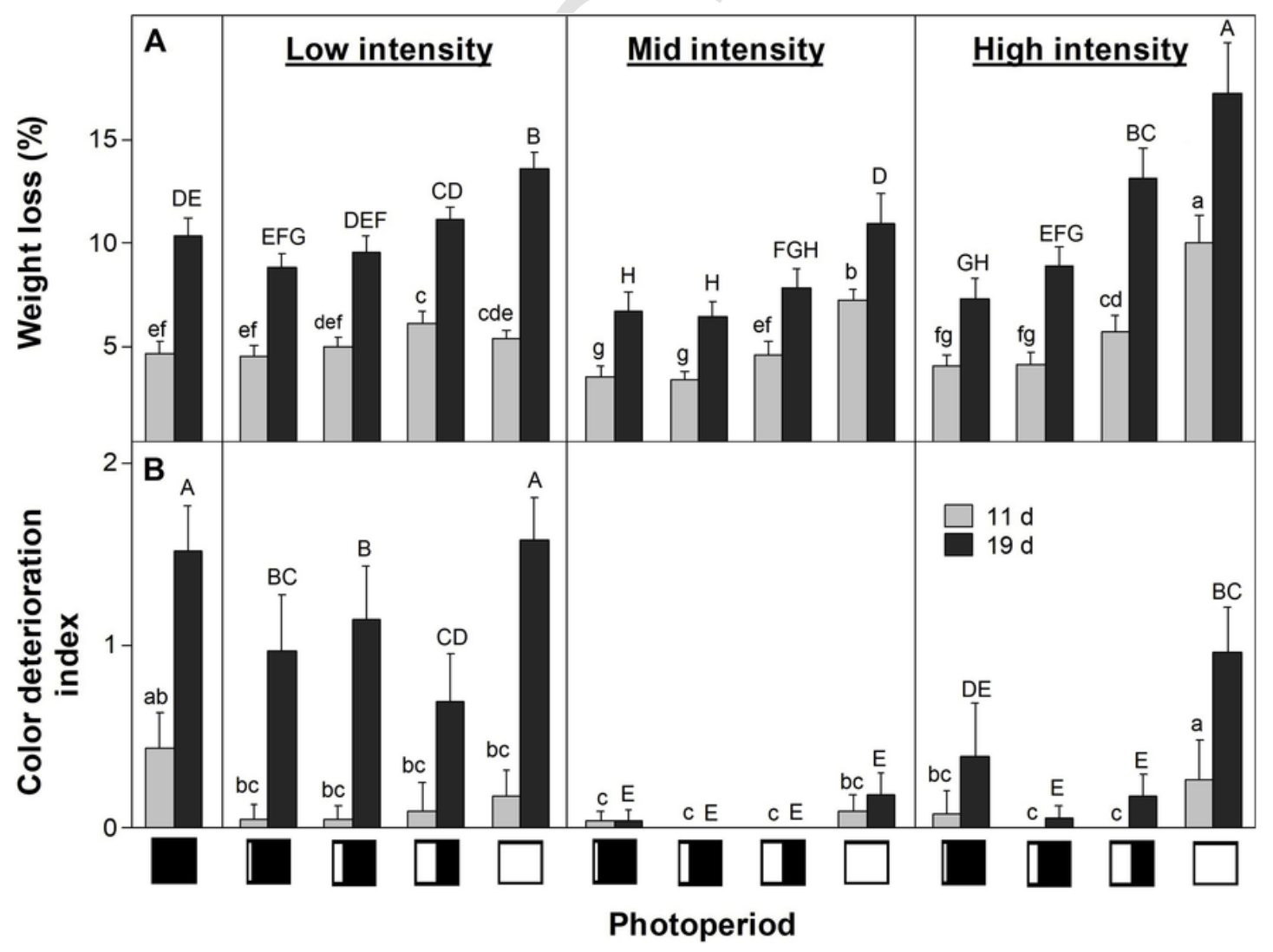

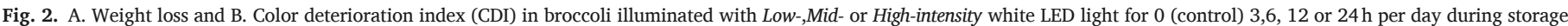

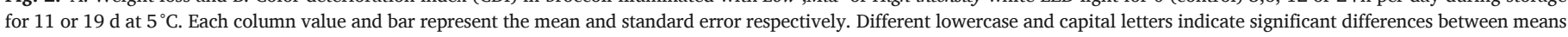
after 11 and $19 \mathrm{~d}$ of storage, respectively, based on a Fisher test at a level of significance of $P<0.05$. 


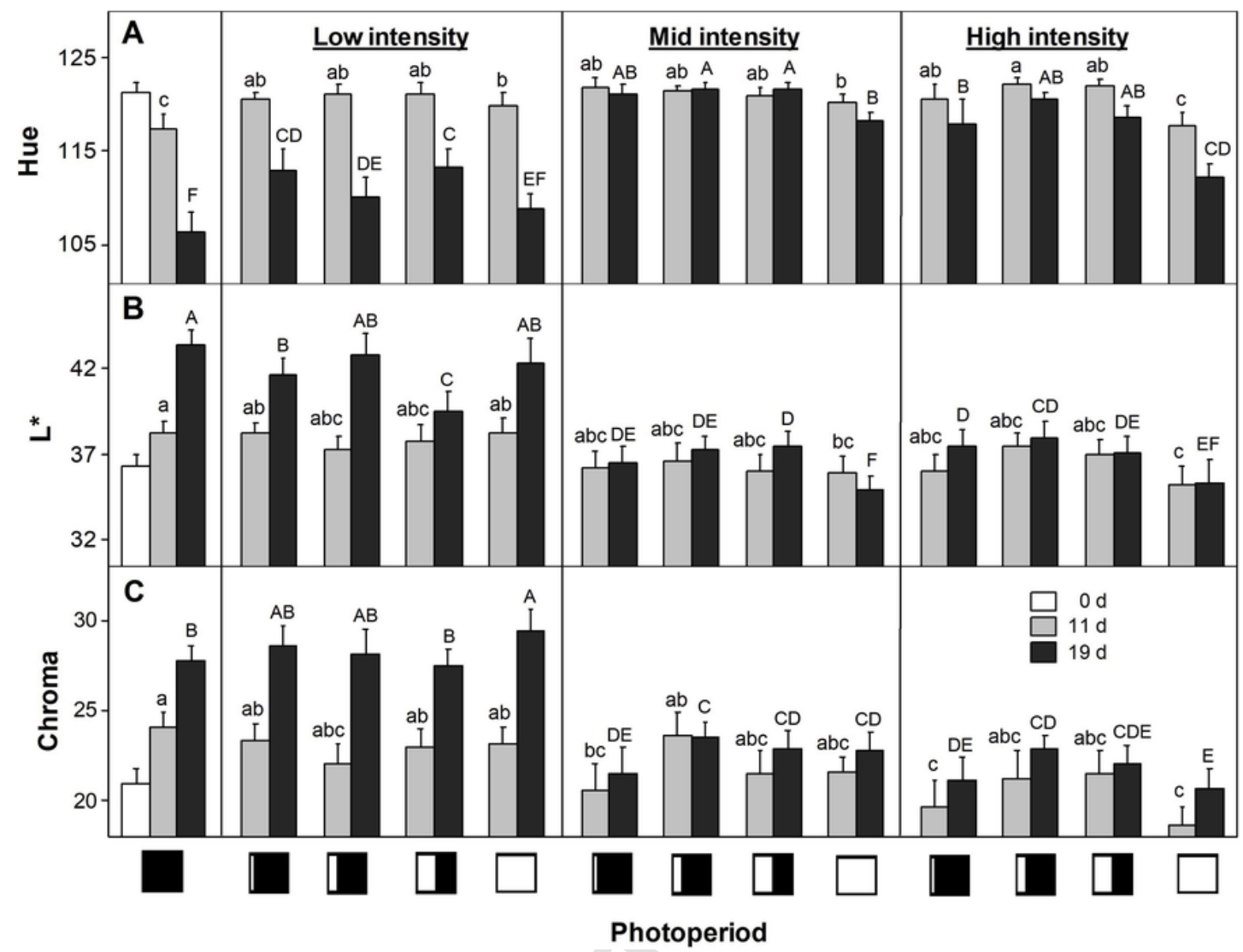

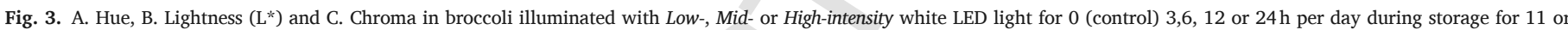

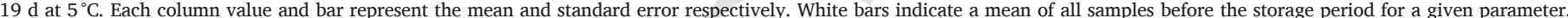

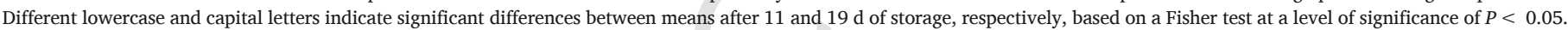

Each tray contained in 15 florets. The trays were located on a display fridge at $5^{\circ} \mathrm{C}$ and illuminated with a $30 \mathrm{~W}$ cool white light source consisting in plates having 66 LED bulbs each (Triano, Model: 10L069ISU7267, Argentina), under the following lighting conditions:
i) Low intensity $(L I)=\left(3.6 \mathrm{~W} \mathrm{~m}^{-2}\right)$;
ii) Mid-intensity $(M I)=\left(9.5 \mathrm{~W} \mathrm{~m}^{-2}\right)$;
iii) High-intensity $(\mathrm{HI})=\left(19.0 \mathrm{~W} \mathrm{~m}^{-2}\right)$.

The three light intensity conditions (Fig. 1A) were achieved by changing the distance between the light source and the packages $(75,58$ and $42 \mathrm{~cm}$ for LI, MI and HI respectively). For each intensity condition tested the trays were subjected to the following light-dark cycles (Fig. 1B):

a) 3:21 = Consisting of a daily cycle of $3 \mathrm{~h}$ illumination followed by $21 \mathrm{~h}$ in darkness;

b) $6: 18=6 \mathrm{~h}$ illumination followed by $12 \mathrm{~h}$ in darkness;

c) $12: 12=12 \mathrm{~h}$ illumination followed by $12 \mathrm{~h}$ in darkness;

d) $24: 0=$ Continuous illumination.

The illumination cycles were repeated daily throughout the storage period. Samples for each photoperiod and storage time were randomly distributed along the storage shelves. One set of broccoli samples stored in darkness at the same temperature was used as a control. Samples were taken after 0,11 or $19 \mathrm{~d}$ of storage and used to determine a color, weight loss, chlorophylls, glucose, fructose and sucrose contents. We also evaluated the level of ascorbic acid, carotenoids and total phenolics. Measurements were done immediately upon sampling, or otherwise samples were frozen in liquid nitrogen and stored at $-80^{\circ} \mathrm{C}$ un- til analysis. Four independent trays were used for each treatment and storage time.

\subsection{Quality assessment}

\subsubsection{Color deterioration index (CDI)}

The color of individual florets was visually assessed by using a 3 point hedonic scale with the following categories: $0=$ dark green $1=$ Light green; 2 = Yellow-green. The CDI was calculated as:

$\mathrm{CDI}=\Sigma$ (Color deterioration category $\times$ № florets in this category)/ Total № of florets

Ten florets were evaluated for each tray and four trays were evaluated for each treatments and storage time.

\subsubsection{Weight loss}

Weight loss was determined by weighing individual florets at the beginning of the experiment and throughout the storage period. Results were expressed in percentage relative to the initial weight. Ten florets were evaluated for each tray and four trays were evaluated for each treatments and storage time.

\subsubsection{Color}

Superficial color of fresh broccoli florets was determined by measuring the $L^{*}, a^{*}$, and $b^{*}$ color scale parameters with a chromameter (Minolta CR400, Osaka, Japan). The Hue angle $(h)$ was calculated as $h=$ $\tan ^{-1}=(b / a)+180^{\circ}$ given that $a^{*}$ was $<0$ and $b^{*}>0$. The chroma was calculated as $\left(a^{* 2}+b^{* 2}\right)^{1 / 2}$. Ten florets were analyzed for each tray and four trays were evaluated for each treatments and storage time. 


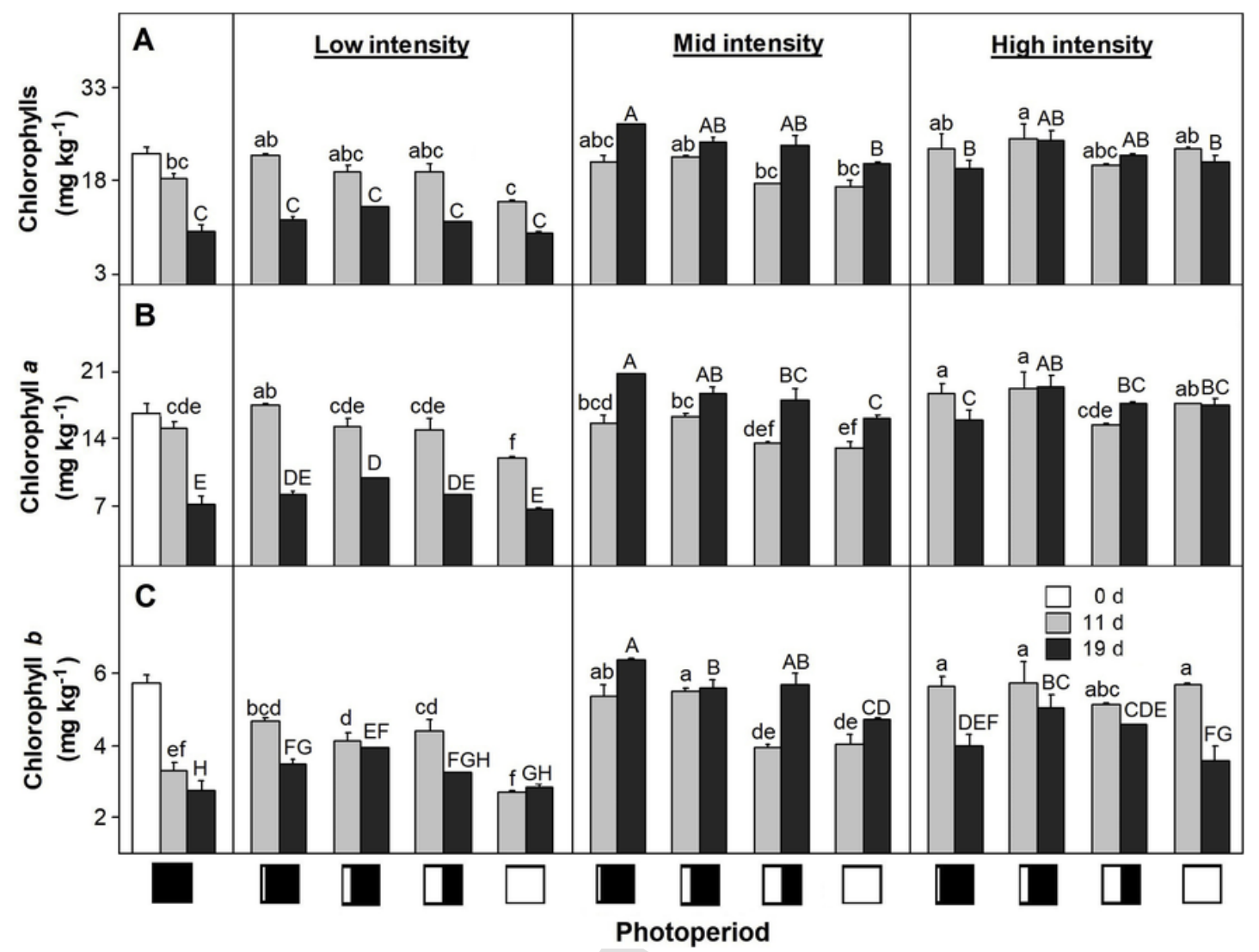

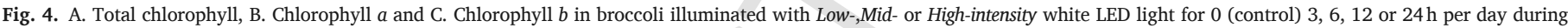

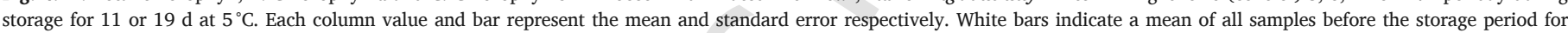

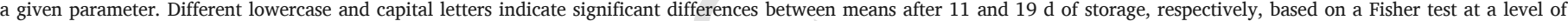
significance of $P<0.05$.

\subsubsection{Chlorophylls and carotenoids}

Frozen broccoli florets were frozen in liquid $\mathrm{N}_{2}$, crushed in a laboratory mill and $0.4 \mathrm{~g}$ of the obtained powder was poured into $5 \mathrm{~mL}$ of acetone/water (80:20), stirred and then centrifuged at $5000 \times g$ for $15 \mathrm{~min}$. The supernatant was used to determine the content of chlorophyll and carotenoids according to Lemoine et al. (2009). Results were expressed in milligram per kilogram on fresh weight basis. Three replicates were done for each treatment and storage time.

\subsubsection{Sugars}

Approximately $50 \mathrm{~g}$ of frozen broccoli were ground in a mill and $0.6 \mathrm{~g}$ of the resulting sample were homogenized in $5 \mathrm{~mL}$ of ethanol and vortexed for $1 \mathrm{~min}$. The mixture was centrifuged at $5000 \times g$ for $10 \mathrm{~min}$ at $4{ }^{\circ} \mathrm{C}$; the supernatant was saved and filtered through $0.2 \mu \mathrm{m}$ RC membrane (Cole-Parmer, USA). For sugar determination, a high-performance liquid chromatograph (Model 1525, WatersCorp., USA) was used, equipped with a refractive index detector (Model IR 2414, Waters Corp., USA) and an Hypersil Gold Amino column $(4.6 \times 250 \mathrm{~mm}, 5 \mathrm{~mm}$, Thermo Sci., USA). Samples were run isocratically in acetonitrile/water $(70 / 30)$ at a flow rate of $1.0 \mathrm{~mL} \mathrm{~min}^{-1}$. Four measurements were done per treatment and storage time evaluated. Results were expressed in $\mathrm{mg}$ $\mathrm{kg}^{-1}$ of sugar on fresh weight basis.

\subsubsection{Ascorbic acid}

Samples were frozen in liquid nitrogen, processed in a mill and approximately $1 \mathrm{~g}$ of the resulting powder was homogenized with $5 \mathrm{~mL}$ of $2.5 \% \mathrm{~m} / \mathrm{v} \mathrm{m}$-phosphoric acid. The mixture was vortexed for $1 \mathrm{~min}$ and then centrifuged at $12,000 \times g$ for $10 \mathrm{~min}$ at $4^{\circ} \mathrm{C}$. The supernatant was saved and filtered through $0.2 \mu \mathrm{m}$ RC membrane. Ascorbic acid
(AsA) determination was done by using a high-performance liquid chromatograph (Model 1525, Waters Corp., USA), fitted with a photo diode array detector and a C18 column $(4.6 \times 150 \mathrm{~mm}, 5 \mathrm{~mm}$, Waters Corp., USA). The mobile phase consisted of $0.5 \% \mathrm{~m} / \mathrm{v}$ metaphosphoric acid/ acetonitrile (93/7) and was run isocratically at a flow rate of $1.0 \mathrm{~mL}$ $\min ^{-1}$. Samples were detected at $254 \mathrm{~nm}$ and AsA identification and quantitation were done by using a calibration curve with an authentic standard. Results were expressed in milligrams per kilogram on fresh weight basis. Four samples were analyzed for each treatment and storage time.

\subsubsection{Total phenolics}

Ethanol extracts were obtained described insection 2.2.5. Fifty microliters of the supernatant was added to $950 \mu \mathrm{L}$ of distilled water and $50 \mathrm{~mL}$ of 1:1 water diluted Folin-Ciocalteu reagent. After $3 \mathrm{~min}, 100 \mu \mathrm{L}$ of a solution containing $20 \% \mathrm{~m} / \mathrm{v} \mathrm{Na}_{2} \mathrm{CO}_{3}$ in $0.1 \mathrm{~mol} \mathrm{~L}^{-1} \mathrm{NaOH}$ were added and samples were incubated at $25^{\circ} \mathrm{C}$ for $90 \mathrm{~min}$ (Singleton et al., 1999). The absorbance was measured in a spectrophotometer at $760 \mathrm{~nm}$ and total phenolics were calculated by using chlorogenic acid (CGA) as standard. Results were expressed as milligrams of CGA equivalents per kilogram on fresh weight basis. Four replicates were analyzed per treatment and storage time analyzed.

\subsection{Statistical analysis}

The experiment was a $4 \times 3 \times 3$ factor (photoperiod $\times$ light intensity $\times$ storage time) design. For each treatment condition four independent trays containing 15 florets each were used. Data were analyzed with ANOVA general lineal model test using InfoStats software. When differences among treatments were significant, the mean values 


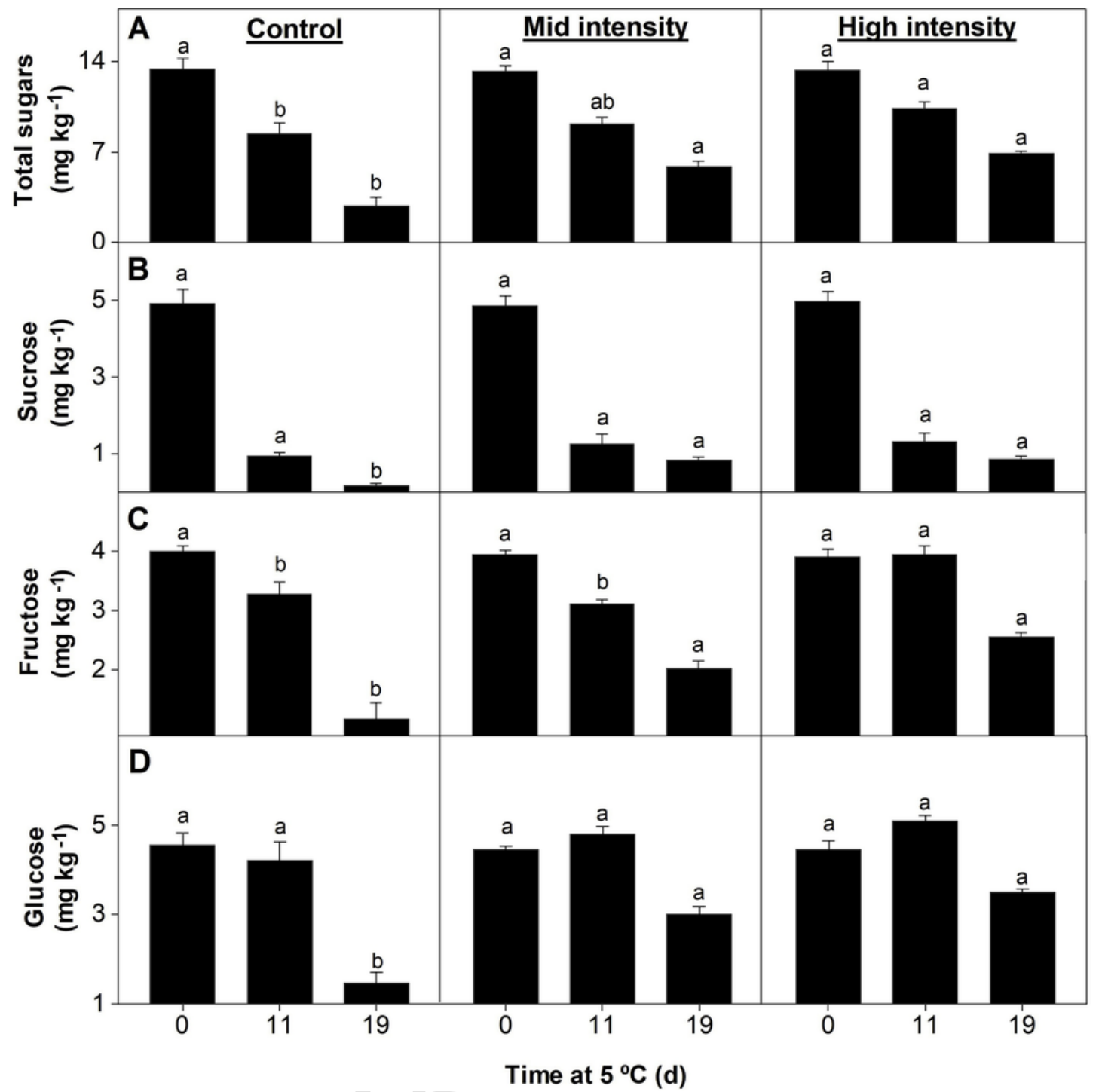

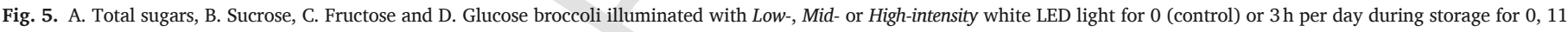

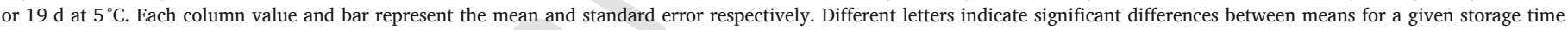
based on a Fisher test at a level of significance of $P<0.05$.

were compared by the least significant difference using the Fisher test $(P<0.05)$

\section{Results and discussion}

\subsection{Weight loss and yellowing}

Mid- and High-intensity treated florets held under continuous light showed after 11d of storage higher weight loss (WL) than dark-stored (control) broccoli (Fig. 2A). Similar results were found for light stored cauliflower (Sanz et al., 2007) and leek (Ayala et al., 2009). Although LEDs are more efficient than incandescent lights, they still generate heat that will favor water loss and that would be expected to have greater impact at longer the treatment and the higher the radiation intensity (Branas et al., 2013). At the last sampling date, when senescence symptoms in the samples were more evident, large differences in weight loss were found among treatments. The effects of light intensity on tissue dehydration after $19 \mathrm{~d}$ of storage were of particular interest: Low-intensity light exposure for 3,6 or $12 \mathrm{~h}$ per day resulted in comparable WL values than dark-stored controls, whereas treatment consisting of 3-12h illumination per day under Mid-intensity light or $3 \mathrm{~h}$ with
High-intensity radiation markedly decreased the extent of sample dehydration. With regards to the photoperiod, for all the radiation intensities evaluated, longer daily exposure to light, led to greater $\mathrm{WL}$. Light exposure may modulate the extent of water loss in green tissues via mechanisms having opposite effects: on one side it may prevent dehydration by delaying cell aging and disorganization (Li et al., 2016). On the other side, light is a known regulator of stomatal opening, not only under field conditions (Kinoshita et al., 2001), but also during storage. Lettuce illumination in storage maintained higher proportion of stomata opened and favored water loss (Martínez-Sánchez et al., 2011). Also, in line with this, kale leaves stored at $1{ }^{\circ} \mathrm{C}$ maintained $90 \%$ of total stomata opened if kept under continuous light, but less than $10 \%$ when stored in darkness (Noichinda et al., 2007). Then, illumination treatments inducing stomata opening might be expected to decrease the resistance to water vapor flux and favor weight loss. Although broccoli sepals are highly rich in stomata (Kunkel, 2019) their dynamics under storage and their responsiveness to postharvest illumination regimes has not been studied so far. This may help to establish whether changes in stomata functionality induced by different light intensity and photoperiod combinations are involved in the differences in tissue WL found herein. In any case, results clearly show that both white 


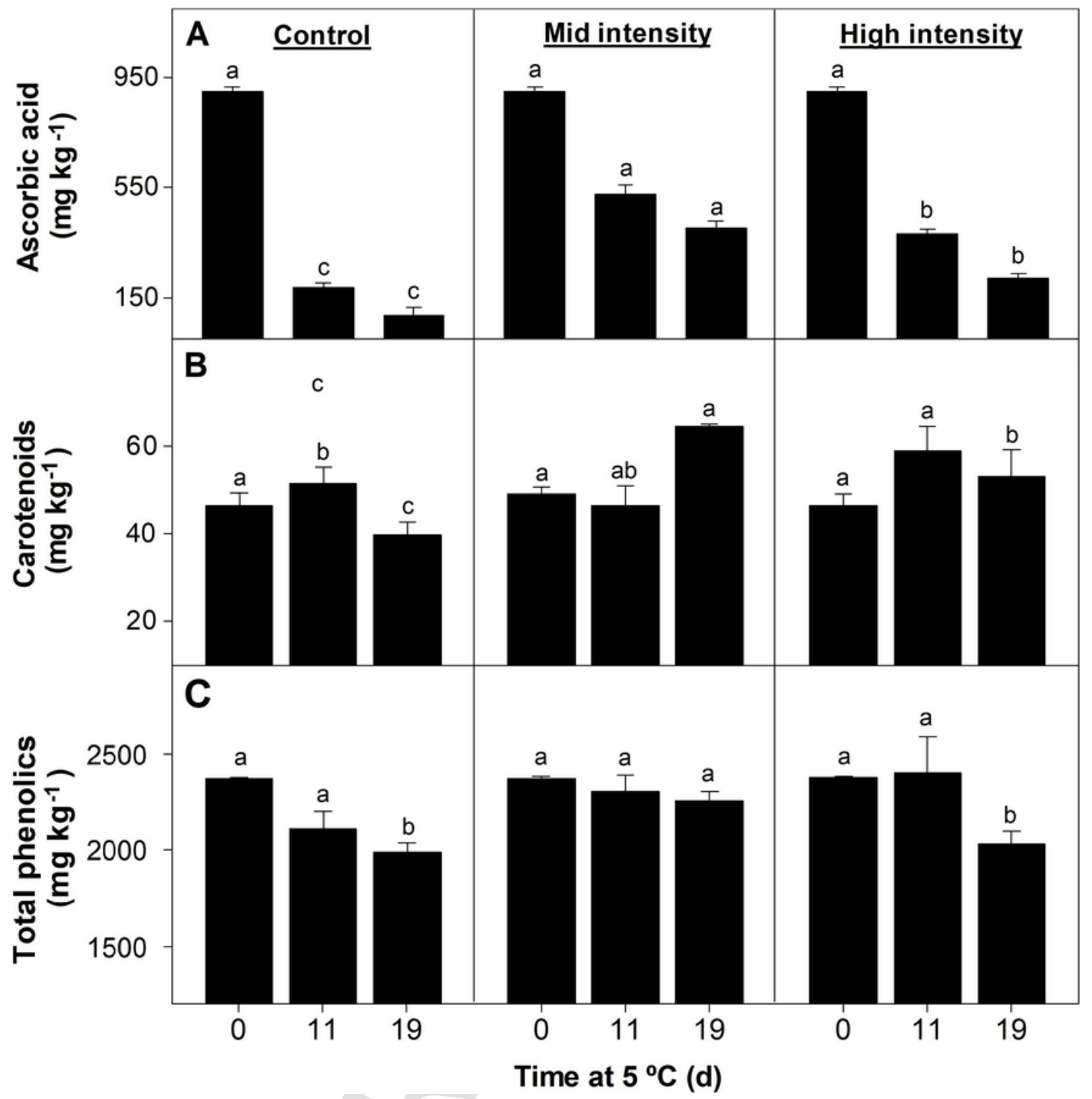

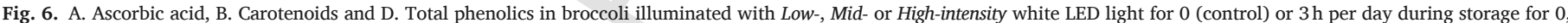

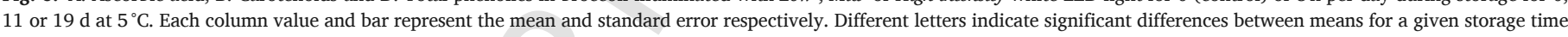
based on a Fisher test at a level of significance of $P<0.05$.

light LED radiation intensity and time of exposition have, even under refrigerated conditions, a significant effect on broccoli susceptibility to dehydration.

Slight color changes were found after $11 \mathrm{~d}$ of storage based on sample visual assessment (Fig. 2B). However, control and continuously illuminated samples already showed incipient symptoms of yellowing. After $19 \mathrm{~d}$, control broccoli presented evident yellowing symptoms (CDI 1.5). Low-intensity illumination treatments were, regardless of the photoperiod, ineffective to prevent yellowing. In contrast, Mid- and High-intensity light exposure significantly delayed color deterioration. Daily light exposure for 3-12 h at both Mid-and High-intensity were highly effective to maintain broccoli color. Indeed, these treatments showed no variations CDI throughout the storage period.

The hue angle of the dark green broccoli prior to storage was ca.120을 (Fig. 3A) and decreased during storage. The color changes were limited until day eleven, but occurred relatively rapidly afterwards. Low-intensity illumination showed comparable changes in the hue angle than control dark-stored samples. All the High-intensity illumination treatments, besides continuous exposure, were effective to preventing the changes of hue values regardless of time of exposure to light $(3,6$ or $12 \mathrm{~h}$ ). In accordance with the results described for vi- sual color assessment, continuous High-intensity light exposure accelerated the drop of the hue angle values. Remarkably, Mid-intensity illumination treatments showed no changes in their hue values throughout the storage period and for all the photoperiods tested. Lightness $\left(L^{*}\right)$ values showed an increasing trend during storage, accompanying broccoli yellowing (Fig. 3B). Like was reported for the hue angle Low-intensity light treated broccoli mostly lacked differences in $L^{*}$ values compared to the control. Contrariwise, Mid- and High-intensity illumination treatments were effective to inhibit the increase in broccoli lightness under all photoperiods evaluated. Color saturation (chroma) also showed an increasing for control and Low-intensity treated broccoli as storage time progressed whereas no modifications were found in Mid- or High-intensity radiation illuminated samples.

The changes in total, $a$ and $b$-chlorophylls in response to postharvest illumination regime are shown in Fig. 4. After $11 \mathrm{~d}$ at $5{ }^{\circ} \mathrm{C}$, moderate (10-20\%) losses were found in control and Low-intensity treated broccoli. At longer times, the chlorophyll content of dark-stored samples showed a rapid decrease. The drop in total chlorophyll recorded in control broccoli resulted from both losses of Chla and Chlb. However, Chlb turnover seemed to star before that of Chla. This is in line with the results reported by Folley and Engel (1999). Broccoli samples stored 
in the light showed a similar trend in chlorophyll content than that of surface color. Treatments with Low-intensity light sources were ineffective to delay chlorophyll turnover, as opposed to Mid- and High-intensity treatments, which remarkably showed no significant losses in total $\mathrm{Chl}$ throughout storage. Only slight reduction in Chlb occurred in continuous illuminated High-intensity treatments towards the end of the storage period. The length of the illumination period had low impact on chlorophyll levels. Thus, for treatments having intensities in the range 9.5-19.0 $\mathrm{W} \mathrm{m}^{-2}$ photoperiods at least as short as $3 \mathrm{~h}$ would suffice to inhibit chlorophyll turnover and color deterioration while minimizing water loss. Overall, results show that the radiation intensity and photoperiod are major factors in determining the efficacy of postharvest white LED illumination treatments to delay broccoli dehydration and yellowing. Mid- or High-intensity irradiation $\left(9.5\right.$ and $\left.19.0 \mathrm{~W} \mathrm{~m}^{-2}\right)$ for periods no longer than $12 \mathrm{~h}$ per day should be recommended.

\subsection{Sugars and antioxidants}

To further characterize the effect of postharvest white LED illumination, we followed the changes in sugars, ascorbic acid, carotenoids and phenolic antioxidants, which may be greatly affected during senescence (Lemoine et al., 2009; Rybarczyk-Plonska et al., 2014). Measurements were conducted in the dark stored control and in addition in broccoli illuminated for $3 \mathrm{~h}$ per day with Mid- or High-intensity light, which were among the most effective treatments in terms of color retention. The concentration of total soluble sugars (TS) was prior to storage c.a. $14 \mathrm{mg} \mathrm{kg}^{-1}$ (Fig. 5A), with sucrose, glucose and fructose being present at similar levels (Fig. 5B-D). Sucrose was found to decrease to a higher extent with storage than glucose and fructose. This likely resulted from the hydrolysis by invertases involved in the regeneration of the pool of monosaccharides required to feed respiration (Eason et al., 2007).

The content of total sugars showed in all three treatments a decreasing trend. However, the rate of sugar loss was a function of illumination conditions used in retail. After $19 \mathrm{~d}$ of storage period, control dark-stored broccoli lost $80 \%$ of their TS content. Instead, samples held in the light maintained $\sim 50 \%$ of their initial sugar pool. Similarly, to these results, improved sugar content in response to light treatments were found in celery (Zhan et al., 2014a), kale (Noichinda et al., 2007) and spinach (Toledo et al., 2003). The basis for this effect that seems a consistent response across species, it is not fully understood. The respiration rate of fresh vegetables has been shown to increase prior to senescence (Costa et al., 2006). Then, this increased fuel demand would affect cell carbon budget and contribute to explain the lower TS content of dark stored senescing broccoli. On the other hand, some authors have speculated that harvested green tissues held in the light may maintain some photosynthetic activity at least at initial times of storage (Toledo et al., 2003; Noichinda et al., 2007; Charles et al., 2018). Unfortunately, few studies have supported this with direct measurement of $\mathrm{CO}_{2}$ fixation conducted at storage temperatures.

Broccoli is considered one of the top vegetables in terms of health-promoting glucosinolates and antioxidants (Bjorkman et al., 2011; Ma et al., 2014; Wang et al., 2017). The level of sulfur rich glucisonolates have been known to shown relatively small changes under refrigerated storage (Winkler et al., 2007) as opposed to antioxidant compounds, which may be significantly lost even under proper temperature management (Lemoine et al., 2009; Rybarczyk-Plonska et al., 2014). We then monitored the changes in ascorbic acid (AsA), total carotenoids and phenolics in response to the postharvest white light illumination. AsA decreased $80 \%$ after $11 \mathrm{~d}$ of storage and by $95 \%$ at the last sampling date in control dark-stored samples (Fig. $6 \mathrm{~A})$. A clear protective effect was found, and at the end of the storage period AsA content of Mid-intensity illuminated broccoli was 5 times higher than that found in the control. These results are in line with those reported by Zhan et al. (2014a), who detected higher AsA contents in light-stored cauliflower as compared to a dark-stored control. Ma et al. (2014), found that light exposure can upregulate a number of AsA biosynthetic genes in broccoli. However, in other study Rybarczyk-Plonska et al. (2014) found no differences in AsA between broccoli heads stored in the dark or treated with white light $12 \mathrm{~h}$ per day. These disparate results on AsA may obey in part to differences in the radiation intensities used for the illumination treatments. In fact, in the present study, AsA retention differed between Mid- and High-intensity illumination treatments, the former being more effective (Fig. 6A). In addition to the potential light induction of AsA biosynthesis suggested above, an increase ascorbate-depleting reactive oxygen species (ROS) may also explain the poorer performance of samples treated with High-intensity light compared to Mid-intensity illuminated broccoli (Sharma and Dubey, 2004). Future studies determining the influence of light intensity on AsA biosynthetic route and catabolism in refrigerated commodities would be useful.

Carotenoid contents showed no changes in control during storage. In contrast, Mid- and High-intensity light treatments tended to show an increasing trend (Fig. 6B). This is in line with Hasperue et al. (2016a), who found carotenoids accumulation during postharvest storage of broccoli heads exposed to continuous white/blue light. Postharvest light treatments have been also reported to induce carotenoid accumulation in outer leaves of Brussels sprouts (Hasperué et al., 2016b) and refrigerated kale leaves (Noichinda et al., 2007). Light is known to be one of the major effectors inducing carotenoid biosynthesis at least in planta (Lichtenthaler, 2007; Jones, 2018). In fact, carotenoids function in presence of light is to quench thetriplet state of chlorophyll and thus prevent oxidative chloroplast damages (Tracewell et al., 2001; Noichinda et al., 2007; Braidot et al., 2014).

Finally, phenolics showed a decreasing trend during storage (Fig. 6C). Broccoli exposed to Mid-intensity light maintained, at the end of the storage period, higher levels of phenolics than the control. This is in line with work reported by Zhan et al. (2014b), who found, in cauliflower, that postharvest light exposure may induce phenylalanine ammonia lyase, while inhibiting polyphenol oxidase and peroxidase.

\section{Conclusions}

In this work we evaluated the influence of the intensity and photoperiod of white illumination treatments during retail on the shelf-life of cold stored broccoli. Mid-intensity $\left(9.5 \mathrm{~W} \mathrm{~m}^{-2}\right)$ white LED illumination for $3 \mathrm{~h}$ fully inhibited chlorophyll degradation for $19 \mathrm{~d}$ at $5{ }^{\circ} \mathrm{C}$ and delayed sugar losses. The selected treatment also tended to increase carotenoid contents at long storage times, prevented ascorbic acid and phenolic antioxidants losses. Overall, results show that white LED illumination treatments $\left(9.5 \mathrm{~W} \mathrm{~m}^{-2}, 3-12 \mathrm{~h}\right)$ could be a non-chemical way to extend the shelf-life of refrigerated broccoli during retail.

CRediT authorship contribution statement

Federico M. Pintos: Investigation, Methodology. Joaquín H. Hasperué: Investigation, Methodology. Ariel R. Vicente: Writing review \& editing. Luis M. Rodoni: Writing - original draft, Writing review \& editing, Visualization.

\section{Declaration of Competing Interest}

There are no conflicts of interest related with the present submission.

\section{Acknowledgment}

The authors thank the Agencia Nacional de Promoción Científica y Tecnológica (PICT 2015-3690) for financial support.

\section{References}

Ayala, F., Echávarri, J.F., Olarte, C., Sanz, S., 2009. Quality characteristics of minimally processed leek packaged using different films and stored in lighting conditions. Inter. J. Food Sci. Technol 44, 1333-1343. 
Bantis, F., Smirnakou, S., Ouzounis, T., Koukounaras, A., Ntagkas, N., Radoglou, K., 2018. Current status and recent achievements in the field of horticulture with the use of light-emitting diodes (LEDs). ScientiaHort 235, 437-451.

Bjorkman, M., Klingen, I., Birch, A.N.E., Bones, A.M., Bruce, T.J.A., Johansen, T.J., Meadow, R., Molmann, J., Seljasen, R., Smart, L.E., Stewart, D., 2011. Phytochemicals of Brassicaceae in plant protection and human health-influences of climate, environment and agronomic practice. Phytochem. 72, 538-556.

Braidot, E., Petrussa, E., Peresson, C., Patui, S., Bertolini, A., Tubaro, F., Wählby, U., Coan, M., Vianello, A., Zancani, M., 2014. Low-intensity light cycles improve the quality of lamb's lettuce (Valerianellaolitoria [L.] Pollich) during storage at low temperature. Postharvest. Boil. Technol. 90, 15-23.

Branas, C., Azcondo, F.J., Alonso, J.M., 2013. Solid-state lighting: a system review. IEEE Ind. Electron. Mag. 7, 6-14.

Büchert, A.M., Civello, P.M., Martínez, G.A., 2011. Effect of hot air, UV-C, white light and modified atmosphere treatments on expression of chlorophyll degrading genes in postharvest broccoli (Brassica oleracea L.) florets. Sci. Hort. 127, 214-219.

Charles, F., Nilprapruck, P., Roux, D., Sallanon, H., 2018. Visible light as a new tool to maintain fresh-cut lettuce post-harvest quality. Postharvest Biol. Technol. 135, 51-56.

Costa, M.L., Vicente, A.R., Civello, P.M., Chaves, A.R., Martínez, G.A., 2006. UV-C treatment delays postharvest senescence in broccoli florets. Postharvest Biol. Technol. 39, 204-210.

Darré, M., Valerga, L., Araque, L.C.O., Lemoine, M.L., Demkura, P.V., Vicente, A.R., Concellón, A., 2017. Role of UV-B irradiation dose and intensity on color retention and antioxidant elicitation in broccoli florets (Brassica oleracea var. Italica). Postharvest Biol. Technol. 128, 76-82.

Eason, J.R., Ryan, D.J., Watson, L.M., Pinkney, T., Hedderley, D., Christey, M.C., Braun, R.H., Coupe, S.A., 2007. Suppressing expression of a soluble acid invertase (BoINV2) in broccoli (Brassica oleracea) delays postharvest floret senescence and downregulates cysteine protease (BoCP5) transcription. Physiol. Plantarum 130, 46-57.

Fan, X.T., Mattheis, J.P., 2000. Yellowing of broccoli in storage is reduced by 1-methylcyclopropene. Hortscience 35, 885-887.

Folley, P., Engel, N., 1999. Chlorophyll b to chlorophyll a conversion precedes chlorophyll degradation in Hordeumvulgare L.. J. Biol. Chem. 274, 21811-21816.

Fukasawa, A., Suzuki, Y., Terai, H., Yamauchi, N., 2010. Effects of postharvest ethanol vapor treatment on activities and gene expression of chlorophyll catabolic enzymes in broccoli florets. Postharvest Biol. Technol. 55, 97-102.

Ilić, Z.S., Fallik, E., 2017. Light quality manipulation improves vegetable quality at harvest and postharvest: a review. Env. Exp. Bot. 139, 79-90.

Izumi, H., Watada, A.E., Douglas, W., 1996. Optimum $\mathrm{O}_{2}$ or $\mathrm{CO}_{2}$ atmosphere for storing broccoli florets at various temperatures. J. Am. Soc. Hortic. Sci 121, 127-131.

Jin, P., Yao, D., Xu, F., Wang, H., Zheng, Y., 2015. Effect of light on quality and bioactive compounds in postharvest broccoli florets. Food Chem. 172, 705-709.

Jones, M.A., 2018. Using light to improve commercial value. Hortic. Res. 5, 47.

Kinoshita, T., Doi, M., Suetsugu, N., Kagawa, T., Wada, M., Shimazaki, K.I., 2001. Phot1 and phot 2 mediate blue light regulation of stomatal opening. Nature 414, 656

Kunkel, D., 2019. Science Photo Library. Access. In: https://www.sciencephoto.com/ media/801532/view.

Lemoine, M.L., Civello, P., Chaves, A., Martínez, G., 2009. Hot air treatment delays senescence and maintains quality of fresh-cut broccoli florets during refrigerated storage. LWT-Food Sci. Technol. 42, 1076-1081.

Li, L., Lv, F.Y., Guo, Y.Y., Wang, Z.Q., 2016. Respiratory pathway metabolism and energy metabolism associated with senescence in postharvest Broccoli (Brassica oleracea L. var. italica) florets in response to $\mathrm{O}_{2} / \mathrm{CO}_{2}$ controlled atmospheres. Postharvest Biol. Technol. 111, 330-336.

Lichtenthaler, H.K., 2007. Biosynthesis, accumulation and emission of carotenoids, $\alpha$-tocopherol, plastoquinone, and isoprene in leaves under high photosynthetic irradiance. Photosynthesis Res. 92, 163-179.
Liu, J.D., Goodspeed, D., Sheng, Z., Li, B., Yang, Y., Kliebenstein, D.J., Braam, J., 2015 Keeping the rhythm: light/dark cycles during postharvest storage preserve the tissue integrity and nutritional content of leafy plants. BMC Plant Biol. 15, 92.

Ma, G., Zhang, L., Setiawan, C.K., Yamawaki, K., Asai, T., Nishikawa, F., Maezawac, S., Satod, H., Kanemitsue, N., Katoa, M., Kato, M., 2014. Effect of red and blue LED light irradiation on ascorbate content and expression of genes related to ascorbate metabolism in postharvest broccoli. Postharvest Biol. Technol. 94, 97-103.

Martínez-Hernández, G.B., Artés-Hernández, F., Gómez, P.A., Formica, A.C., Artés, F., 2013. Combination of electrolysed water, UV-C and superatmospheric $\mathrm{O}_{2}$ packaging for improving fresh-cut broccoli quality. Postharvest Biol. Technol. 76, 125-134.

Martínez-Sánchez, A., Tudela, J.A., Luna, C., Allende, A., Gil, M.I., 2011. Low oxygen levels and light exposure affect quality of fresh-cut Romaine lettuce. Postharvest Biol. Technol. 59, 34-42.

Moreira, M.D.R., Roura, S.I., Ponce, A., 2011. Effectiveness of chitosan edible coatings to improve microbiological and sensory quality of fresh cut broccoli. LWT-Food Sci. Technol. 44, 2335-2341.

Noichinda, S., Bodhipadma, K., Mahamontri, C., Narongruk, T., Ketsa, S., 2007. Light during storage prevents loss of ascorbic acid, and increases glucose and fructose levels in Chinese kale (Brassica oleracea var. alboglabra). Postharvest Biol. Technol. 44, 312-315.

Olarte, C., Sanz, S., Echávarri, J.F., Ayala, F., 2009. Effect of plastic permeability and exposure to light during storage on the quality of minimally processed broccoli and cauliflower. LWT-Food Sci. Technol. 42, 402-411.

Rybarczyk-Plonska, A., Hansen, M.K., Wold, A.B., Hagen, S.F., Borge, G.I.A., Bengtsson, G.B., 2014. Vitamin C in broccoli (Brassica oleracea L. var. italica) flower buds as affected by postharvest light, UV-B irradiation and temperature. Postharvest Biol. Technol. 98, 82-89.

Sanz, S., Olarte, C., Ayala, F., Echávarri, J.F., 2009. Evolution of quality characteristics of minimally processed asparagus during storage in different lighting conditions. J. Food Sci. 74, 296-302

Sanz, S., Olarte, C., Echávarri, J.F., Ayala, F., 2007. Influence of exposure to light on the sensorial quality of minimally processed cauliflower. J. Food Sci. 72, S012-S018.

Sharma, P., Dubey, R.S., 2004. Ascorbate peroxidase from rice seedlings: properties of en zyme isoforms, effects of stresses and protective roles of osmolytes. Plant Sci. 167, 541-550.

Singleton, V.L., Orthofer, R., Lamuela-Raventós, R.M., 1999. Analysis of total phenols and other oxidation substrates and antioxidants by means of Folin-Ciocalteu reagent. Met. Enzymol. 299, 152-178.

Toledo, M.E.A., Ueda, Y., Imahori, Y., Ayaki, M., 2003. L-ascorbic acid metabolism in spinach (Spinaciaoleracea L.) during postharvest storage in light and dark. Postharvest Biol. Technol. 28, 47-57.

Tracewell, C.A., Vrettos, J.S., Bautista, J.A., Frank, H.A., Brudvig, G.W., 2001. Carotenoid photooxidation in photosystem II. Arch. Biochem. Biophys. 385, 61-69.

Wang, B., Jin, X., Chen, X.D., 2017. Investigation on the relationship between the integrity of food matrix and nutrient extraction yield of broccoli. LWT-Food Sci. Technol. 85, $170-174$.

Winkler, S., Faragher, J., Franz, P., Imsic, M., Jones, R., 2007. Glucoraphanin and flavonoid levels remain stable during simulated transport and marketing of broccoli (Brassica oleracea var. italica) heads. Postharvest Biol. Technol. 43, 89-94.

Xiao, Z., Lester, G.E., Luo, Y., Xie, Z.K., Yu, L.L., Wang, Q., 2014. Effect of light exposure on sensorial quality, concentrations of bioactive compounds and antioxidant capacity of radish microgreens during low temperature storage. Food Chem. 151, 472-479.

Zhan, L., Hu, J., Pang, L., Li, Y., Shao, J., 2014. Effects of light exposure on chlorophyll, sugars and vitamin C content of fresh-cut celery (Apiumgraveolens var. dulce) petioles. Int. J. Food Sci. Technol. 49, 347-353.

Zhan, L., Hu, J., Pang, L., Li, Y., Shao, J., 2014. Light exposure reduced browning enzyme activity and accumulated total phenols in cauliflower heads during cool storage. Postharvest Biol. Technol. 88, 17-20. 